that the risks of renal failure and hypertension persist for decades. Children with reflux nephropathy should be carefully followed up during their childhood and adolescence. During pregnancy they should be managed as high risk patients, and obstetricians and nephrologists should cooperate closely. Establishment of continuity of treatment between paediatricians and renal physicians is essential when young patients are transferred from paediatric care.

We thank Ulla-Britt Zetterholm, Nils Lindvall, Dora Hånberg, and Irja Nilsson for their skilful technical help. This study was supported by grants from the T Nilsson, $M$ Bergwall, Thurins, and O E Ericsson Foundations; Scandia Incorporated; the Swedish Society of Medicine; the Swedish National Federation for Kidney Patients; and the Medical Research Council.

1 Wallace DMA, Rothwell DL, Williams DI. The long-term follow-up of surgically treated vesicoureteric reflux. Br f Urol 1978;50:479-84

2 Brunner $\mathrm{FP}$, Broyer M, Brynger $\mathrm{H}$, et al. Demography of dialysis and ransplantation in children in Europe 1985. Nephrol Dial Transplant $1988: 3: 235-43$.

Kincaid-Smith P. Glomerular lesions in atrophic pyelonephritis and reflux nephropathy. Kidney Int 1975;8(suppl 4):81-3.

+ Torres VE, Velosa JA, Holley KE, Kelalis PP, Stickler GB, Kurtz SB. The progression of vesicoureteral reflux nephropathy. Ann Intern Med 1980;92:

5 Holland NH, Kotchen T, Bathena D. Hypertension in children with chronic pyelonephritis. Kidney Int 1975;8(suppl 5):243-51.

6 Heale WF. Hypertension and reflux nephropathy. Austr Paediatr f 1977:13.56.

7 Heale WF, Shannon T, Utley WLF, Rolleston GL. Familial and hereditary reflux nephropathy. In: Hodson J, Kincaid-Smith P, eds. Reflux nephro-
reale WF, Shannon T, Utley WLF, Rolleston GL. Familial and hereditary pathy. New York: Masson, 1979:48-52

8 Dillon MJ, Smellie JM. Peripheral plasma renin activity, hypertension and renal scarring in children. Contrib Nephrol 1984;39:68-80

9 Jacobson SH, Kjellstrand CM, Lins L-E. Role of hypervolaemia and renin in the blood pressure control of patients with pyelonephritic renal scarring. Acta Med Scand 1988;224:47-53.

10 Hodson CJ. Radiological diagnosis of pyelonephritis. Proceedings of the Royal Society of Medicine 1959;52:669-72.
11 Smellie J, Edwards D, Hunter N, Normand ICS, Prescod N. Vesico-ureteric reflux and renal scarring. Kidney Int 1975;8(suppl 4):65-72.

12 Hodson CJ, Wilson S. Natural history of chronic pyelonephritic scarring. BrMed F 1965;ii: 191-4.

13 Arze RS, Ramos JM, Owen JP, et al. The natural history of chronic pyelonephritis in the adult. Qf Med 1982;51:396-410.

4 Verrier-Jones K, Asscher AW, Verrier-Jones ER, Mattholie K, Leach $\mathrm{K}$, Thomson GM. Glomerular filtration rate in schoolgirls with covert bacteriuria. Br Med f 1982;285:1307-10.

15 Smellie J, Edwards D, Normand ICS, Prescod N. Effect of vesicoureteric reflux on renal growth in children with urinary tract infection. Arch Dis Child 1981;56:593-600.

16 Jacobson SH, Källenius G, Lins L-E, Svenson SB. Symptomatic recurrent urinary tract infections in patients with renal scarring in relation to fecal colonization with P-fimbriated Escherichia coli. F Urol 1987;137:693-6.

17 Jacobson SH, Källenius G, Lins LE, Svenson SB. P-fimbriae receptors in patients with chronic pyelonephritis. F Urol 1988;139:900-3.

18 Still JL, Cottom D. Severe hypertension in children. Arch Dis Child 1967; 42:34-9.

9 Verrier-Jones K, Verrier-Jones ER, Asscher AW. Covert urinary tract infections in children. In: Asscher AW, Brumfitt W, eds. Microbial diseases in nephrology. Chichester: Wiley, 1986:225-39.

20 Savage JM, Koh CT, Shah V, Barratt TM, Dillon MJ. Five year prospective study of plasma renin activity and blood pressure in patients with longstanding reflux nephropathy. Arch Dis Child 1987;62:678-82.

21 Karlsson FA, Wibell L, Evrin PE. Beta-2-microglobulin in clinical medicine.

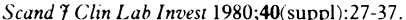

22 Kincaid-Smith P. Glomerular lesions in atrophic pyelonephritis and reflux nephropathy. Kidney Int 1975;8:81-3

23 Weaver E, Crasswell P. Pregnancy outcome in women with reflux nephropathy - a review of experience at the Royal Women's Hospital Brisbane, 1977-1986. Aust NZ J Obstet Gynaecol 1987:27:106-11.

24 Kincaid-Smith P. Pregnancy-related renal disease. In: Seldin DW, Giebisch G, eds. The kidney: physiology and pathophysiology. New York: Raven, 1985:2043-58

25 Becker GJ, Ihle BU, Fairley KF, Bastos M, Kincaid-Smith P. Effect of pregnancy on moderate renal failure in reflux nephropathy. Br Med $\mathrm{J}$ $1986 ; 292: 796-8$

26 Sacks SH, Verrier-Jones K, Roberts R, Asscher AW. Effect of symptomatic bacteriuria in childhood on subsequent pregnancy. Lancet 1987;ii:991-4.

27 Berg UB, Johansson B. Age as a main determinant of renal functional damage in urinary tract infection. Arch Dis Child 1983;58:963-9.

28 Pylkkänen J, Vilska J, Koskimies $\mathrm{O}$. The value of level diagnosis of childhood urinary tract infection in predicting renal injury. Acta Paediatr Scand $1981 ; 70: 879-83$
Littlemore Hospital, Oxford OX4 4XN Max Marshall, MB, registrar in psychiatry

Correspondence to: Flat 2 , 99 St Clements, Oxford OX 4 $1 \mathrm{AR}$.

\title{
Collected and neglected: Are Oxford hostels for the homeless filling up with disabled psychiatric patients?
}

\author{
Max Marshall
}

\begin{abstract}
Objective-To assess the severity of psychiatric symptoms among residents of hostels for homeless people.

Design-Survey of residents in two hostels in Oxford, comprising three weeks of background fieldwork, a demographic questionnaire, and rating behaviour over two weeks with a behavioural rating scale (REHAB) and mental state with the brief psychiatric rating scale.
\end{abstract}

Setting-Two hostels for homeless people in Oxford

Subjects -146 Medium to long term residents, of whom 48 were selected by hostel workers by the following criteria: continuous residence for at least two months, signs of persistent severe mental disability, and difficulty in coping independently in the community. Two subjects died during the study; three (previously long term psychiatric inpatients) declined to be assessed on the psychiatric scale.

Main outcome measure-Behavioural disturbance and mental state.

Results - Only a third of the total sample had been born in Oxfordshire. Subjects had been accepted into the hostel either by arrangement with the local psychiatric service (22) or straight off the streets (26); 43 had had a previous (non-drug related) psychiatric admission. Subjects were significantly more likely than other residents to have spent longer $(>80$ weeks) in a hostel in the past three years $(\mathbf{p}<\mathbf{0 \cdot 0 2})$. With reference to norms for deviant behaviour, the 46 subjects assessed showed considerable deviant behaviour (average weekly scores: 0 (11 subjects), 1 (14), 2-3 (16), and $\geqslant 4$ (5)) not significantly different from that expected in moderately to severely handicapped psychiatric inpatients $\left(\chi^{2}=1 \cdot 3, \mathbf{d f}=3, \mathrm{p}>0.7\right) ; 22$ had scores equivalent to those in most severely handicapped inpatients. Of the $\mathbf{4 3}$ subjects assessed with the psychiatric rating scale, 16 had symptoms of neurosis, 29 of florid psychosis, and 32 of a deficit state. Symptoms of deficit state were positively correlated with ratings of low social activity on the behavioural scale (Spearman's rank correlation coefficient $0 \cdot 30, p=0 \cdot 03$ ).

Conclusions-Hostels are having to care for long term severely affected psychiatric patients discharged into the community. The suitability of the services offered to such subjects should be assessed.

\section{Introduction}

The presence of mentally disordered "street people" in every major town and city alerted the public in the United States to the unforeseen deficiencies of an ambitious programme of deinstitutionalisation. ${ }^{1}$ Surprisingly, although a similar and no better planned policy has been adopted in Britain, ${ }^{2}$ equivalent numbers of conspicuously mentally ill people do not seem to be living on the streets. This might reflect a cultural difference, in that homeless mentally ill people in 
Britain may be more willing to accept help from the state and from charitable institutions and are consequently more likely to congregate in facilities that attempt to resettle the homeless than on the streets. If this is so then the most severely disabled members of this group, for whom resettlement in independent accommodation is not a viable option, will probably collect in such facilities, swamping their resources and perhaps leading to the development of new miniinstitutions, which may offer an inferior quality of psychiatric care. ${ }^{3}$

Previous studies of mentally ill people living in hostels for the homeless have tended to be limited to analysis by demographic features and diagnostic categories alone. ${ }^{+6}$ Their usefulness is limited as they disclose little about the degree of disability and hence the actual burden of care taken on by these hostels. Moreover, the diagnostic categories used are inherently unreliable or entail the use of standardised diagnostic techniques, which are difficult to apply to the most severely disabled people, whose tolerance of lengthy interviews is limited.

The present study is probably unique as it avoids the limitations of a diagnostic approach by instead assessing the level of disability of subjects with chronic and severe mental disability who are living long term in hostels for the homeless in Oxford. It aims at comparing the level of disability in this homeless population with that of more familiar groups such as long stay mentally ill hospital patients.

\section{Subjects and methods}

The study was explicitly designed to counteract two key methodological problems: firstly, the tendency of these highly disorganised and often suspicious people to resist assessment actively, ${ }^{\circ}$ and, secondly, the difficulty of obtaining detailed ratings in such an inaccessible setting. ${ }^{9}$ Consequently the methods were chosen for their economy, reliability, and robustness.

Subjects were all medium to long term residents of the two main hostels for the homeless in Oxford. They were selected initially by experienced hostel workers on the basis of three written criteria, which were explained in detail beforehand; these were that the subjects had been in continuous residence for at least two months, that throughout the past two months they had shown signs of persistent, severe mental disability, and that were the hostel to be closed they would have grave difficulty in looking after themselves and in finding shelter. Five potential subjects were subsequently excluded because they had all been in the care of the mental handicap services. Basic demographic information was collected on the residents who were not eligible for the study so that later comparisons might be made with the study group.

A demographic questionnaire, a psychiatric rating scale (brief psychiatric rating scale) developed by Krawiecka et al, ${ }^{10}$ and a behavioural rating scale known as REHAB " were used to assess the patients and were supported with data from hostel records and psychiatric notes. I completed the questionnaire after interviewing the subject and a care worker who knew him or her well. The brief psychiatric rating scale was specifically designed for rating severity of psychiatric symptoms in long stay inpatient populations and consists of eight items each rated on a five point scale. It is short, easy to use, and its reliability in such populations has been shown. In this study three subscores were derived from the basic eight items, one representing neurotic symptoms, one florid psychotic symptoms, and one symptoms of a deficit state. Interrater agreement on the scale was assessed during the study (coefficients of concordance for the subscales representing neurosis, psychosis, and deficit state $0.81,0.84$, and 0.82 , respectively (Kendall's coefficient of concordance)).

The behavioural assessment scale consists of two sections: that on deviant behaviour (seven items) records the frequency of embarrassing or disruptive behaviour, whereas that on general behaviour ( 16 items) refers to deficits in normal behaviour and is assessed on a visual analogue scale. In addition to recording overall scores in these two categories the scale also analyses general behaviour in terms of five subfactor scores: social activity, speech skills, speech disturbance, self care, and community skills. The behavioural assessment scale may be completed by any rater who has observed the subject in his or her place of residence for one week; in this study all raters were experienced hostel staff. To achieve interrater reliability two one hour group training sessions were given, as recommended. ${ }^{11}$ More elaborate studies of reliability could not be achieved given the constraints of the setting. The use of the behavioural assessment scale did not entail any disruption of normal hostel routine, nor did it take much time, having been designed specifically for unskilled users.

The study began with three weeks of fieldwork in each hostel, during which I acted essentially as a new hostel worker in the hope that I would become a familiar face and so increase compliance in the subsequent interviews. I also had the opportunity to observe the behaviour of the subjects and ensure that the selection criteria had been properly applied. After completion of the fieldwork and psychiatric ratings all members of the study group had their behaviour rated over two weeks. These ratings were later averaged to give a more representative sample of behaviour than for one week alone. The data were analysed with an Apricot Xen personal computer, and non-parametric statistical tests were used for all tests of significance except for comparisons of age and length of stay, for which a two tailed $t$ test was used. The study was approved by the local research ethical committee.

\section{Results}

In all, 48 long term psychiatrically disabled residents (four women) were identified from a total population of 146 in the two hostels. Roughly a third (15) of the sample had been born in Oxfordshire, another third (16) came from the south of England, mainly London, and most of the remainder (13) came from Scotland, Wales, and Ireland. Their mean age was $48 \cdot 1$ (SD 12.4) years, and they were not significantly older than the other hostel residents (mean age $49 \cdot 2$ (13.4) years; $\mathrm{p}>0 \cdot 2$ ).

They seemed to have arrived in the hostels in two main ways: by arrangement with the local psychiatric service ( 22 subjects), and by being taken literally off the streets (26). Most of those taken off the streets (16 subjects) had arrived in Oxford shortly before admission, but seven were local long term psychiatric patients who had lost contact with the local services and become homeless. The remaining three had lived in Oxford for several years before admission; two had had occasional contact with local psychiatric services. Of the 16 subjects who had arrived in Oxford shortly before admission to the hostels, 10 had been long term psychiatric patients in other parts of the country, three had had intermittent psychiatric admissions or consultations, and only three had never seen a psychiatrist. Considering the group as a whole, $34(70 \cdot 8 \%)$ had had previous psychiatric admissions in Oxford and 16 (33\%) had had admissions elsewhere (excluding admissions for treatment of drug or alcohol dependence). Only five did not have a history of a previous (non-drug related) psychiatric admission, one of whom had spent almost a year in a head injury rehabilitation unit.

There was a clear difference in length of stay in the 
hostels between the chronically disabled and other residents, the chronically disabled being significantly more likely to have spent more than 80 weeks in one of the hostels in the past three years $(p<0.02) ; 21$ of the chronically disabled had lived in the hostels for the whole of the past three years. Most were socially isolated, only six had ever married, and 20 had not been in contact with any relatives for over a year.

Although at the time of assessment all had been free of drugs and alcohol free for at least two months, the incidence of previous drug and alcohol problems was high $(21 \%$ and $27 \%$ life time prevalence respectively). The rate of previous imprisonment was also high; 23 had served a custodial sentence and 13 had been arrested inside the past year. Two of the subjects died during the study, and behavioural ratings were completed for only 46 , of whom 43 were also rated with the brief psychiatric rating scale, the other three declining to be interviewed. All of the subjects were rated for deviant behaviour on the behavioural scale: the average weekly score in 11 was 0 , in 14 was 1 , in 16 was between 2 and 3 , and in five was $\geqslant 4$. A score of 2 , for example, indicated that either a particular type of deviant behaviour was being displayed frequently during an average week or that two types of deviant behaviour had occurred once each in that week. The total deviant behaviour score was given by the sum of scores for each individual item of deviant behaviour. Within the two week period 23 subjects were recorded as talking to themselves, 20 displayed verbal aggression, and 12 were sexually offensive. Other types of deviant behaviour were less common, but all, including actual physical violence (two subjects) and self injury (one), were recorded.

With reference to the norms for deviant behaviour on the behavioural scale the overall amount of deviant behaviour was considerable and did not differ signifcantly from that expected if the study had been conducted in a hospital ward of moderately to severely handicapped long stay patients $\left(\chi^{2}=1 \cdot 3, \mathrm{df}=3, \mathrm{p}>0 \cdot 7\right)$. The relative rates of occurrence of individual items of deviant behaviour were as predicted by the norms, except for sexually offensive behaviour, which was more common than expected; unfortunately, the norms do not allow for assessment of the significance of this finding.

Table I summarises the scores for general behaviour. Twenty two subjects (almost half of the sample) scored so poorly that if they were psychiatric inpatients, according to the norms they would fall into the category of most severely handicapped. Another 12 were in the category of moderate handicap, whereas only 12 were in the category of least handicap, usually described by the norms as having potential for discharge. On the five subfactors of general behaviour, between 21 and 28 subjects of the group had scores in the top half of the long stay norms. The distribution of scores for each subfactor did not differ significantly from that which would be expected from inpatients who had spent more than 10 years in hospital.

The scores of mental state on the brief psychiatric rating scale were subdivided into three subfactor scores as described above. Overall 16 of the 43 subjects interviewed had clinically significant neurotic symptoms, 29 had florid psychotic symptoms, and 32 showed clinically significant symptoms consistent with

TABLE I-Summary of scores on general behaviour rating scale in 46 long term psychiatrically disabled residents in two hostels in Oxford

\begin{tabular}{lccc}
\hline & \multicolumn{3}{c}{ Score } \\
\cline { 2 - 4 } & $0-40$ & $40-64$ & $64-144$ \\
\hline $\begin{array}{l}\text { No (\%) of subjects } \\
\text { Category according to norms on scale }\end{array}$ & $\begin{array}{c}12(26) \\
\text { Potential for discharge }\end{array}$ & $\begin{array}{c}12(26) \\
\text { Moderate handicap }\end{array}$ & $\begin{array}{c}22(48) \\
\text { Severe handicap }\end{array}$ \\
\hline
\end{tabular}

a defect state; only five had no clinically significant symptoms of either florid psychosis or deficit state, three of whose psychiatric notes indicated that they had had psychotic symptoms in the past. All three subjects who refused the interview had been long term psychiatric inpatients. Table II summarises the

TABLE II-Correlations between behavioural ratings and ratings of psychiatric symptoms (Spearman's rank correlation coefficients) in long term psychiatrically disabled residents

\begin{tabular}{lccc}
\hline & \multicolumn{3}{c}{ Behavioural ratings } \\
\cline { 2 - 4 } & Deviant behaviour & General behaviour & Social activity \\
\hline Florid symptoms & 0.229 & 0.07 & \\
Symptoms of deficit & & 0.15 & $0.30^{\star}$ \\
\hline
\end{tabular}

${ }^{\star} \mathrm{p}=0.03$ (one tailed).

correlations between the scores for deviant and general behaviour scores by the behavioural scale and the brief psychiatric rating scale subfactor scores. Symptoms of a deficit state on examination of mental state positively correlated with ratings of low levels of social activity on the behavioural scale $(p=0.03)$.

\section{Discussion}

The two hostels for the homeless had a substantial population of chronically and severely disabled persons, who had a high level of psychiatric symptomatology and a pattern of deviant behaviour similar to that expected in a ward of long stay psychiatric patients. In terms of skills and abilities half of the sample were functioning so poorly as to fall into the category of the most severely disabled class of long térm psychiatric patients.

The two hostels, staffed by psychiatrically untrained workers and volunteers, were effectively attempting to do the work equivalent to that in two long stay psychiatric wards while also caring for another 98 homeless residents, many of whom have considerable problems with substance abuse. This seems to have arisen as a result of efforts to transfer the care of long term psychiatric patients to the community-almost half of those studied (22) had been referred to the hostels directly by the Oxford psychiatric service. Most of them were very ill indeed. We are witnessing the inadvertent creation of mini-institutions in hostels whose original function was the rehabilitation of homeless alcoholic subjects. The different strategies adopted by the two hostels to meet this unsolicited challenge was impressive. An analysis of the met and unmet needs of the psychiatric residents might help to disclose the extent to which the services offered by the hostels suit the many problems of this very disabled population and is an obvious direction for further research.

This research was supported by a grant from the Wellcome Trust. I thank Dr John Hall and Ms Lorna Hogg for their help with this research; Ms C Cherrad for her help in preparing the manuscript; and all staff at the two hostels, in particular, Mike Hall, Clive Bishop, and Mark Thompson for their enthusiastic support of the research.

1 Jones RE. Street people and psvchiatry: an introduction. Hosp Community P'sychratry 1983;35:899-907.

2 Lowry S. Concern for discharged mentally ill patients. Br Med f 1989;298:20910.

3 Bassuk EL. Is homelessness a mental health problem? Am $f$ Psychiatry 1984;141:1546-50.

4 Lodge Patch IC. Homeless men in London: 1. Demographic findings in a lodging house sample. Br f Psychiatry 1971;118:313-7.

5 Fisher PJ, Shapiro S, Breakey WR, Anthony JC, Kramer M. Mental health and social characteristics of the homeless: a survey of mission users. $A m \mathcal{F}$ Public Health 1984;76:519-24.

6 Scott R, Gaskell PG, Morrell DC. Patients who reside in common lodging cott R, Gaskell PG, Morrell DC.
houses. BrMed F 1966;ii:1561-4.

7 Cohen NL, Putnam JF, Sullivan AM. The mentally ill homeless: isolation and Cohen NL, Putnam JF, Sullivan AM. The mentally ill ho
adaptation. Hosp Community Psychiatry 1984;35:922-4. 
8 Bachrach LL. The homeless mentally ill and the mental health services: an analytical review of the literature. In: Lamb HR, ed. The homeless mentally ill: a task force report of the American Psychiatric Association. Washington American Psychiatric Association, 1984:75-89.

9 Hogg L, Hall J, Marshall M. Assessing chronic mental patients: new approaches to assessing the movement of patients through care facilities. Psychosocial Rehahilitation fournal (in press
10 Krawiecka M, Goldberg D, Vaughn M. A standardised psychiatric assessment scale for rating chronic psychotic patients. Acta Psychiatr Scand 1977;55 299-308

11 Baker R, Hall JN. REHAB: a new assessment instrument for chronic psychiatric patients. Schizophr Bull 1988;14:97-111.

(Accepted 24 fuly 1989)

\title{
Use of medical record linkage to study readmission rates
}

\author{
J Henderson, M J Goldacre, M J Graveney, H M Simmons
}

\begin{abstract}
Readmission rates after inpatient care were studied by using routinely collected data from the Oxford record linkage study for $1968-85$. Discharges from hospital and subsequent admissions were identified for people who were both resident and treated in the area covered by the linkage study. Rates were calculated for readmissions within 28 days after discharge from the first, index event. Readmission rates for elective readmissions after elective index admissions rose from $3.5 \%$ in 1968 to $7 \cdot 1 \%$ in 1985 . Those for elective readmissions after immediate (emergency or accident) index admissions rose from $2.4 \%$ to $3.5 \%$ during the same period. Emergency readmissions after an immediate index admission rose from $4 \cdot 0 \%$ to $7 \cdot 0 \%$, and emergency readmissions after an elective index admission rose from $1 \cdot 3 \%$ to $2 \cdot 5 \%$. All these increases were significant. The rise in elective readmissions may in part reflect a trend towards planned discharge with the expectation of readmission. The rise in emergency readmissions, which has been fairly gradual over many years, may, in some cases, be due to pressure on resources and inappropriately short lengths of stay. Further evidence is required to confirm or refute this.
\end{abstract}

Readmission rates are one of the few potential measures available from routine statistics for assessing outcome, but due consideration must be given to issues of method and interpretation.

\section{Introduction}

Current interest in studying readmissions to hospital after discharge from inpatient care is due to several reasons. Firstly, hospital admission rates in England have increased for many years, but as routine hospital statistics are based on unlinked counts of admissions the extent to which these statistics are inflated by an increase in readmissions rather than primary admissions is generally unknown. Information about readmissions is therefore required to distinguish between changes in admission rates due to a change in numbers of patients treated and those due to a change in multiple admissions per person. Secondly, readmission is one measure of prognosis routinely available data on readmission rates for patients in particular diagnostic groups may be useful to clinicians in predicting the course of patients' illnesses. Thirdly, if patients who are at high risk of unintended readmission can be identified approaches to their care may be implemented that reduce the likelihood of readmission. ${ }^{2-6}$

There has also been interest in the use of readmission rates as possible indicators of quality of care. Two admissions for an individual patient may or may not be related. When they are related the readmission may be planned as part of a programme of phased care or it may be unforeseen. Unforeseen readmissions may be a consequence of the natural course of the patient's disease or may result from suboptimal care during the first admission. Because of the second possibility variation in quality of care, either over time or between different hospitals, might result in variation in readmission rates. The package of performance indicators currently used in the NHS has been criticised for its lack of outcome indicators, ${ }^{78}$ and in the search for outcome indicators that could be obtained from routinely collected statistics the use of readmission rates is under consideration. ${ }^{9}$

The National Steering Group on Health Services Information (the Körner committee) recommended the use of a unified district medical record system so that each patient treated within a district would have the same medical record number for each admission. ${ }^{10}$ The use of this number in the computerised abstract of the hospital admission is intended to facilitate the linkage of episodes in hospital for individual patients within a district. Now that health authorities are implementing the recommendations of the Körner committee the means will exist to calculate readmission rates for the various purposes described above.

We analysed readmission rates by using data from the Oxford record linkage study for 1968-85. We report some broad trends in these rates and discuss some of the methodological issues that need consideration in analysing readmission rates.

\section{Population and methods}

The Oxford record linkage study includes brief abstracts of hospital inpatient records. These are similar to the abstracts that have been collected elsewhere in England as Hospital Activity Analysis in the past and that are collected currently as the Hospital Episode System. For many years these data have been collected in the Oxford region in ways such that records relating to the same patient can be linked together. ${ }^{112}$ These data have been collected in two of the eight health districts in the Oxford region since 1968 (population about 850000 ) and in six of the districts since 1975 (population about 1.9 million). The data presented here cover hospital discharges for 1968-85 in all specialties except psychiatry and obstetrics.

We used the following definitions and criteria for selection of records. An index event in each year was defined as the first recorded admission and subsequent discharge for each patient in the year. First discharges for a patient within a calendar year were excluded if the patient's admission occurred within 28 days after a discharge in the previous year (identified by linking records for each patient back to the previous year). Index events longer than 28 days in duration were excluded. Patients who died during the index event or the following 28 days were excluded. The time period for readmission was taken as being within 28 days after the date of discharge from the index event. When a patient had several readmissions only the first was tabulated. The analysis was confined to patients who 